\title{
Calculations of Ion-ion Interactions, Densities, and Different Volumes of Barium Diphenylamine Sulfonate in Ethanol-water at Different Temperatures
}

\author{
Elsayed T. Helmy ${ }^{1,2 \star}$, Esam A. Gomaa ${ }^{2}$, Elsayed M. Abou Eleef ${ }^{3}$ \\ ${ }^{1}$ Marine Pollution Research Lab., National Institute of Oceanography and Fisheries, Ministry of Scientific Research, \\ Alexandria, Egypt, ${ }^{2}$ Department of Chemistry, Faculty of Science, Mansoura University, 35516 Mansoura, Egypt, \\ ${ }^{3}$ Department of Basic Science, Delta Higher Institute for Engineering \& Technology, 35681 Dakhlia, Mansoura, Egypt
}

\section{ABSTRACT}

The aim of this work is to calculate ion-ion interaction, dielectric constant, density of organic-aqueous mixtures of ethanol-water, density of saturated solutions of barium diphenylamine sulfonate (BDPA), salvation volumes (Van der Waals volume $\mathrm{V}_{\mathrm{W}}$, molar volume $\mathrm{V}_{\mathrm{M}}$, and electrostriction volume $\mathrm{V}_{\mathrm{e}}$ ), and solvated radii $\left(\mathrm{r}_{\mathrm{o}}\right)$ from solubility experiments. It was found that values of the log activity coefficient $\left(\gamma_{ \pm}\right)$of BDPA in $\left(\mathrm{EtOH}-\mathrm{H}_{2} \mathrm{O}\right)$ mixture were decreases by increasing in the content of the organic solvent used. The values of the $\log \gamma_{+}$found to decrease with the increase in temperature. The densities and the molar volumes of the saturated solutions of BDPA decrease by increasing ratio of EtOH and also increase by increasing in temperature. All the electrostriction volumes calculated for BDPA having negative values. The electrostriction volumes increase in negativity on increasing the percentages of the organic solvent. The solvated radii of BDPA are increased as the organic solvent content increase and as the temperature increase.

Key words: Barium diphenylamine sulfonate, ion-ion interactions, solubility, solvation volumes

\section{INTRODUCTION}

The ionic strength of a solution is a measure of the concentration of ions in that solution. Ionic compounds, when dissolved in water, dissociate into ions. The total electrolyte concentration in solution will affect important properties such as the dissociation or the solubility of different salts. One of the main characteristics of a solution with dissolved ions is the ionic strength. Various models have been used to predict the cosolvent/water solubility profiles. These include parabolic and log-linear models. The log-linear model of Yalkowsky and Rosemann ${ }^{[1]}$ describes an exponential increase in non-polar drug solubility with a linear increase in cosolvent concentration. There are also numerous parabolic models that have been used to predict the cosolvent/water solubility profile for semi-polar solutes. Paruta et al. ${ }^{[2]}$ correlated the cosolvent solubility with a parabolic function of the dielectric constant of the solvent mixture. Martin et al. ${ }^{[3-5]}$ proposed a parabolic relationship between solute solubility and the solubility parameter of a solvent mixture. Recently, Ruckenstein et al. ${ }^{[6]}$ applied fluctuation theory to generate a new parabolic relationship. These parabolic relationships are based on regular solution theory. As was shown by Hilderbrand and Scatchard ${ }^{[7]}$ and later reiterated by Yalkowsky, ${ }^{[8]}$ regular solution theory

${ }^{\star}$ Corresponding author:

Email: stalaat41@yahoo.com

http://dx.doi.org/10.20530/IJIBCS426

ISSN 2047-9093 @ 2017 is not applicable to solutions where hydrogen bonding or ionic interactions are dominant. Ethanol is the most commonly used cosolvent due to its low toxicity and low cost. Ethanol/water systems have the most data available, and therefore, ethanol will be used as the model solvent for this study. A lot of published data ${ }^{[9-12]}$ for BDPA and other substances that states that they are very important materials for different fields.

\section{MATERIALS AND METHODS}

\section{Materials}

High grade of barium diphenylamine sulfonate ethanol was supplied from Merck, double-distilled water that has measured specific conductance $2 \times 10^{-7} \mathrm{~S} / \mathrm{cm}$.

\section{Preparation of Mixed Solvent and Saturated Solutions}

The mixed solvent, (ethanol + water by percent values of ethanol $=0,20,40,60,80$, and $100 \%$ by volume), was prepared from double-distilled water and fairly pure ethanol. Then, saturated solutions of BDPA were prepared by dissolving different amounts in closed test tubes containing different (ethanol + water) mixtures. The tubes were placed in a shaking thermostat (Model Gel) for 4 days till equilibrium reached. The solubility, $S$ (mole/kg.solvent), of BDPA in the mixed solvent at different temperature was determined gravimetrically by the solvent evaporating method. All the solubility experiments were repeated at least 3 times and the results were averaged. 


\section{RESULTS AND DISCUSSION}

\section{Ion-ion Interaction Calculations}

For an ionic compound, with the formula $\mathrm{AB}_{2}$, we may consider the following equilibrium in its saturated solution at a given constant temperature.

$$
\mathrm{AB}_{2}(\mathrm{~s}) \leftrightarrow \mathrm{A}_{(\mathrm{aq})}^{2+}+2 \mathrm{~B}^{-}{ }_{(\mathrm{aq})}, \quad \mathrm{K}_{\mathrm{sp}(\mathrm{th})}=\mathrm{a}_{+} \cdot \mathrm{a}_{-}
$$

Where, $\mathrm{K}_{\mathrm{sp}(\mathrm{th})}$ denotes the thermodynamic solubility product constant and $\mathrm{a}_{+}$and $\mathrm{a}_{-}$refer to activity of $\mathrm{A}^{2+}$ and $\mathrm{B}^{-}$in the solution, respectively. If the solubility of $\mathrm{AB}_{2}$ is very low, it may replace the activity of each ion by its concentration, so,

$\mathrm{K}_{\mathrm{sp}(\mathrm{th})}=4 \mathrm{~s}_{\mathrm{o}}{ }^{3}$

Where, $\mathrm{s}_{\mathrm{o}}$ represents the molarity of $\mathrm{BA}_{2}$ in the very dilute solution. The electrostatic interaction becomes very small and the ion association phenomenon may be negligible (the activity coefficient $\gamma_{ \pm} \sim 1$ ). ${ }^{[13-16]}$

At low concentration, the activity coefficient may be determined using the Debye-Hückel limiting law.

Ion-ion interaction is a function of the mean activity coefficient $\left(\gamma_{+}\right)$of the ions. There are several theoreticallybased expressions that can be used to estimate the activity coefficients. At very low concentration, the electrostatic interaction becomes very small and the ion association phenomenon may be negligible (the activity coefficient $\left.\gamma_{ \pm} \sim 1\right) .[17,18]$

At low concentration, the activity coefficient may be determined using the Debye- Hückel limiting law:

$\log \gamma_{ \pm}=-Z_{+} Z_{-} A \sqrt{I}$ applicable for $\mathrm{I}<10^{-2} \mathrm{M}$

Where, $\mathrm{Z}_{+}$and $\mathrm{Z}_{-}$are the charges of ions in solutions, $\mathrm{A}=1.823 \times 10^{6}(\varepsilon . \mathrm{T})^{-3 / 2}$, the ionic strength, I, defined as, $\mathrm{I}=\frac{1}{2} \sum_{\mathrm{i}} \mathrm{m}_{\mathrm{i}} \mathrm{z}_{\mathrm{i}}^{2} \quad\left(\mathrm{z}_{\mathrm{i}}\right.$ is the charge on ion $\mathrm{i}$, and $\mathrm{m}_{\mathrm{i}}$ is the molality of ion i) and the ionic strength, I emphasizes the charges of ions because the charge numbers occur as their squares.

At relatively high concentration, the electrostatic interaction becomes very large. ${ }^{[19,20]}$ The activity coefficient may be determined using the extend Debye-Hückel law:

$\log \gamma_{ \pm}=\frac{-\mathrm{Z}_{+} \mathrm{Z}_{-} \mathrm{A} \sqrt{\mathrm{I}}}{\mathrm{I}+\mathrm{Br}^{\circ} \sqrt{\mathrm{I}}}$ for $\mathrm{I}<10^{-1} \mathrm{M}$

Where $\mathrm{B}=50.29 \times 10^{8}(\varepsilon \mathrm{T})^{-1 / 2}$, and $\mathrm{r}^{\circ}$ is the solvated radius.
At high concentrations, activity coefficients of electrolyte solutions can be determined using the Davies equation ${ }^{[20]}$ which is an empirical extension of Debye-Hückel theory. The final form of the equation gives the mean molal activity coefficient, $\gamma_{ \pm}$, of an electrolyte which dissociates into ions having charges $Z_{+}$and $Z_{-}$as a function of ionic strength, $I_{\text {. }}$

$\log \gamma_{ \pm}=-Z+Z-A\left(\frac{\sqrt{1}}{I+\sqrt{1}}-0.3 I\right)$

The second term, $0.3 \mathrm{I}$, goes to zero as the ionic strength goes to zero, so the equation reduces to the Debye-Hückel equation at low concentration. However, as concentration increases, the second term becomes increasingly important, so the Davies equation can be used for solutions too concentrated to allow the use of the Debye-Hückel equation.

The results of the ionic strength for BDPA in $\left(\mathrm{EtOH}-\mathrm{H}_{2} \mathrm{O}\right)$ mixture are illustrated in Table 1 . The values of the $\log \gamma_{+}$ for BDPA in $\left(\mathrm{EtOH}-\mathrm{H}_{2} \mathrm{O}\right)$ mixture are illustrated in Table 2 are shown in Figure 1.

It was found that values of the $\log \gamma_{ \pm}$of BDPA were decreases by increasing in the content of the organic solvent used (EtOH) due to decrease in its solubility which lead to a decrease of the electrostatic interaction becomes and the ion association. The values of the $\log \gamma_{ \pm}$found to decrease with the increase in temperature due to a decrease of the electrostatic interaction becomes and the ion association.

\section{Density Measurements}

Density of (organic-aqueous) mixtures

The results of the density measurements of the (organicaqueous) mixtures (EtOH- $\left.\mathrm{H}_{2} \mathrm{O}\right)$ at different temperatures $(293.15,298.15,303.15$, and $308.15 \mathrm{~K})$ are reported in Table 3.

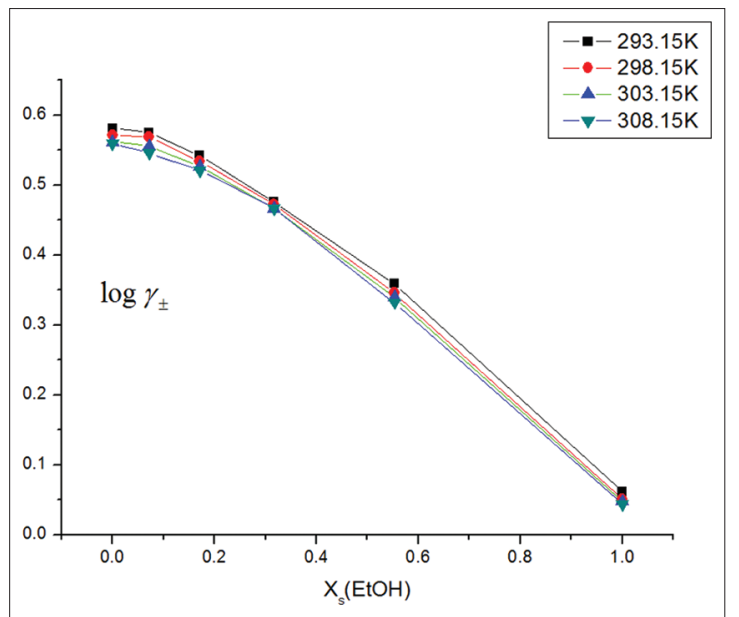

Figure 1: Relation between the activity coefficient $\left(\log \gamma_{+}\right)$of BDPA and the mole fraction of EtOH $\left(\mathrm{X}_{\mathrm{s}}\right)$ in mixed solvents at different temperatures 


\section{Density of the saturated solutions}

Table 4 summarizes the density of the saturated solutions of $\mathrm{BDPA}$ in $\left(\mathrm{EtOH}-\mathrm{H}_{2} \mathrm{O}\right)$ mixtures, at different temperatures $(293.15,298.15,303.15$, and $308.15 \mathrm{~K})$. It is obvious that the densities of the saturated solutions of BDPA decrease by increasing ratio of $\mathrm{EtOH}$ and also increases by increasing in temperature.

\section{Calculation of the Solvation Volumes}

From density and molal solubility measurements of the saturated solutions of BDPA in $\left(\mathrm{EtOH}-\mathrm{H}_{2} \mathrm{O}\right)$ mixtures, the molar volumes $(\mathrm{V})^{[20,21]}$ are calculated, at different temperatures $(293.15,298.15,303.15$, and $308.15 \mathrm{~K}$ ) according to Equation (6):

$\mathrm{V}=\frac{\mathrm{M}}{\mathrm{d}}$

Where, $\mathrm{M}$ is the molecular weight of BDPA $\mathrm{d}$ is the density of the solution. The molecular weights of the binary solvents are calculated using Equation (7):

$\mathrm{M}=\mathrm{X}_{\mathrm{S}(1)\left(\mathrm{H}_{2} \mathrm{O}\right)} \cdot \mathrm{M}_{\left(\mathrm{H}_{2} \mathrm{O}\right)}+\mathrm{X}_{\mathrm{S}(2)(\mathrm{O} . \mathrm{S})} \cdot \mathrm{M}_{(\mathrm{O} . \mathrm{S})}$

Where, $\mathrm{M}_{\left(\mathrm{H}_{2} \mathrm{O}\right)}$ and $\mathrm{X}_{\mathrm{S}(2) \text { (O.S) }}$ are the molecular weights of water and organic solvent, respectively, $\mathrm{X}_{\mathrm{S}(1)\left(\mathrm{H}_{2} \mathrm{O}\right)}$ and $\mathrm{X}_{\mathrm{S}(2)(\mathrm{O} . \mathrm{S})}$ are the mole fractions of water and the organic solvents used by are calculated by applying Equation (8):

Table 1: lonic strength (I) for BDPA in $\left(\mathrm{EtOH}-\mathrm{H}_{2} \mathrm{O}\right)$ mixed solvents at different temperatures

\begin{tabular}{lccccc}
\hline \multirow{2}{*}{$\begin{array}{l}\text { EtOH } \\
\text { vol. \% }\end{array}$} & $\mathrm{X}_{\mathrm{s}}$ & \multicolumn{4}{c}{ lonic strength, I } \\
\cline { 3 - 6 } & & $\mathbf{2 9 3 . 1 5 \mathrm { K }}$ & $\mathbf{2 9 8 . 1 5} \mathrm{K}$ & $\mathbf{3 0 3 . 1 5} \mathrm{K}$ & $\mathbf{3 0 8 . 1 5} \mathrm{K}$ \\
\hline 0 & 0 & 0.604 & 0.6369 & 0.6704 & 0.6884 \\
20 & 0.0788 & 0.1171 & 0.1213 & 0.1344 & 0.1423 \\
40 & 0.1857 & 0.115 & 0.1198 & 0.1222 & 0.1224 \\
60 & 0.3391 & 0.1127 & 0.1171 & 0.1191 & 0.1202 \\
80 & 0.577 & 0.1115 & 0.1159 & 0.1171 & 0.1186 \\
100 & 1 & 0.1098 & 0.1148 & 0.116 & 0.1176 \\
\hline
\end{tabular}

Table 2: Log activity coefficient $\left(\log \gamma_{ \pm}\right)$for BDPA in $\left(\mathrm{EtOH}-\mathrm{H}_{2} \mathrm{O}\right)$ mixed solvents at different temperatures

\begin{tabular}{lccccc}
\hline \multirow{2}{*}{$\begin{array}{l}\text { EtOH } \\
\text { vol. } \%\end{array}$} & $\mathrm{X}_{\mathrm{s}}$ & \multicolumn{4}{c}{$\log \gamma_{ \pm}$} \\
\cline { 3 - 6 } & & $\mathbf{2 9 3 . 1 5 \mathrm { K }}$ & $\mathbf{2 9 8 . 1 5} \mathrm{K}$ & $\mathbf{3 0 3 . 1 5} \mathrm{K}$ & $\mathbf{3 0 8 . 1 5} \mathrm{K}$ \\
\hline 0 & 0 & 0.5511 & 0.5513 & 0.5516 & 0.5494 \\
20 & 0.0788 & 0.5755 & 0.5689 & 0.5558 & 0.546 \\
40 & 0.1857 & 0.5425 & 0.5334 & 0.5268 & 0.5212 \\
60 & 0.3391 & 0.4758 & 0.4729 & 0.4661 & 0.4663 \\
80 & 0.577 & 0.3588 & 0.346 & 0.3397 & 0.3322 \\
100 & 1 & 0.0619 & 0.0508 & 0.0473 & 0.0439 \\
\hline
\end{tabular}

$$
\mathrm{X}_{\mathrm{S}(1)} \text { by wt. }=\frac{\frac{\mathrm{Vol} . \%(1) \times \mathrm{d}(1)}{\mathrm{M}}}{\frac{\mathrm{Vol} . \%(1) \times \mathrm{d}(1)}{\mathrm{M}_{1}}+\frac{\mathrm{Vol} . \%(2) \times \mathrm{d}(2)}{\mathrm{M}_{2}}}
$$

Where, $\mathrm{d}_{(1)}$ and $\mathrm{d}_{(2)}$ are the densities of the organic solvent and water, respectively, and $\mathrm{M}_{1}$ and $\mathrm{M}_{2}$ are the molecular weights of the organic solvent and water, respectively, vol. \% (1) and vol. \% (2) are the volume percentages of the organic solvent and water, respectively.

The packing density (i.e., the relation between the Van der Waals volumes and the partial molar volumes) of relatively large molecules $(>40)$ is found to be constant. Therefore, it is possible to calculate the Van der Waals volumes $\left(\mathrm{V}_{\mathrm{w}}\right)$ of BDPA in $\left(\mathrm{EtOH}-\mathrm{H}_{2} \mathrm{O}\right)$ salt mixtures in at different temperatures $(293.15,298.15,303.15$, and $308.15 \mathrm{~K}$ ) by applying Equation (9).

Packing density $(\mathrm{P})=\frac{\mathrm{V}_{\mathrm{w}}}{\mathrm{V}}=0.661 \pm 0.017$

Where, $\mathrm{V}_{\mathrm{w}}$ and $\mathrm{V}$ are the Van der Waals and partial molar volumes, respectively.

The electrostriction volume $\left(\mathrm{V}_{\mathrm{e}}\right)^{[21,22]}$ which is the volume of the solute compressed by the solvent is calculated using Equation (10).

$\mathrm{V}_{\mathrm{e}}=\mathrm{V}_{\mathrm{w}}-\mathrm{V}$

Table 3: Density $\left(d_{0}\right)$ of $\left(E t O H-H_{2} O\right)$ mixed solvents at different temperatures

\begin{tabular}{lcccc}
\hline \multirow{2}{*}{ EtOH vol. \% } & \multicolumn{4}{c}{$\left(\mathbf{d}_{\mathrm{o}}\right)$} \\
\cline { 2 - 5 } & $\mathbf{2 9 3 . 1 5} \mathrm{K}$ & $\mathbf{2 9 8 . 1 5} \mathbf{K}$ & $\mathbf{3 0 3 . 1 5} \mathrm{K}$ & $\mathbf{3 0 8 . 1 5} \mathbf{K}$ \\
\hline 0 & 1.0004 & 0.997 & 0.9942 & 0.9912 \\
20 & 0.9853 & 0.982 & 0.9789 & 0.9758 \\
40 & 0.9643 & 0.9612 & 0.9577 & 0.9544 \\
60 & 0.9335 & 0.9306 & 0.9264 & 0.9229 \\
80 & 0.8836 & 0.8811 & 0.8756 & 0.8717 \\
100 & 0.7889 & 0.7873 & 0.7789 & 0.7738 \\
\hline
\end{tabular}

Table 4: Density (d) of saturated solution of BDPA in (EtOH- $\left.\mathrm{H}_{2} \mathrm{O}\right)$ mixed solvents at different temperatures

\begin{tabular}{lcccc}
\hline \multirow{2}{*}{ EtOH vol. \% } & \multicolumn{4}{c}{ (d) } \\
\cline { 2 - 5 } & $\mathbf{2 9 3 . 1 5} \mathrm{K}$ & $\mathbf{2 9 8 . 1 5} \mathrm{K}$ & $\mathbf{3 0 3 . 1 5} \mathrm{K}$ & $\mathbf{3 0 8 . 1 5} \mathrm{K}$ \\
\hline 0 & 1.53 & 1.61 & 1.734 & 1.835 \\
20 & 1.207 & 1.211 & 1.214 & 1.217 \\
40 & 1.163 & 1.165 & 1.167 & 1.169 \\
60 & 1.111 & 1.114 & 1.116 & 1.119 \\
80 & 1.05 & 1.053 & 1.057 & 1.063 \\
100 & 1.013 & 1.019 & 1.025 & 1.029 \\
\hline
\end{tabular}


Table 5: Molar volume (V), Van der Waals volume $\left(\mathrm{V}_{w}\right)$, electrostriction volume $\left(\mathrm{V}_{\mathrm{e}}\right)$, and solvated radii $\left(\mathrm{r}_{\mathrm{o}}\right)$ of BDPA in different $\left(\mathrm{EtOH}-\mathrm{H}_{2} \mathrm{O}\right)$ mixed solvents at $293.15 \mathrm{~K}\left(\mathrm{~cm}^{3} \cdot \mathrm{mol}^{-1}\right)$

\begin{tabular}{lcccc}
\hline EtOH vol. \% & $\mathbf{v}$ & $\mathbf{v}_{w}$ & $\mathbf{v}_{\mathrm{e}}$ & $\mathbf{r}_{\mathrm{o}}$ \\
\hline 0 & 412.87 & 272.91 & -140.0 & 4.6246 \\
20 & 521.01 & 344.39 & -176.6 & 5.0050 \\
40 & 540.78 & 357.46 & -183.3 & 5.0673 \\
60 & 566.15 & 374.22 & -191.9 & 5.1452 \\
80 & 598.81 & 395.81 & -203.0 & 5.2430 \\
100 & 619.59 & 409.55 & -210.0 & 5.3060 \\
\hline
\end{tabular}

Table 6: Molar volume (V), Van der Waals volume $\left(\mathrm{V}_{\mathrm{w}}\right)$, electrostriction volume $\left(\mathrm{V}_{\mathrm{e}}\right)$, and solvated radii $\left(\mathrm{r}_{\mathrm{o}}\right)$ of BDPA in different $\left(\mathrm{EtOH}-\mathrm{H}_{2} \mathrm{O}\right)$ mixed solvents at $298.15 \mathrm{~K}\left(\mathrm{~cm}^{3} \cdot \mathrm{mol}^{-1}\right)$

\begin{tabular}{lcccc}
\hline EtOH vol. $\%$ & $\mathbf{v}$ & $\mathbf{v}_{w}$ & $\mathbf{v}_{\mathrm{e}}$ & $\mathbf{r}_{\mathrm{o}}$ \\
\hline 0 & 392.22 & 259.26 & -133.0 & 4.5467 \\
20 & 519.33 & 343.28 & -176.1 & 4.9994 \\
40 & 539.94 & 356.91 & -183.0 & 5.0644 \\
60 & 564.63 & 373.22 & -191.4 & 5.1405 \\
80 & 597.11 & 394.69 & -202.4 & 5.2379 \\
100 & 615.78 & 407.03 & -208.7 & 5.2956
\end{tabular}

The values of $\mathrm{V}, \mathrm{V}_{\mathrm{w}}$, and $\mathrm{V}_{\mathrm{e}}$ of BDPA in $\left(\mathrm{EtOH}-\mathrm{H}_{2} \mathrm{O}\right)$ mixtures; at different temperatures $(293.15,298.15,303.15$, and $308.15 \mathrm{~K}$ ) are listed in Tables $5-8$, respectively.

In comparing the data of solvation, it was observed that the values of the molar volume of ethanol mixtures with water are increased by increasing the organic solvents content in the mixtures due to the increase in the volume of organic solvent compared to water.

All the electrostriction volumes calculated for BDPA in $\left(\mathrm{EtOH}-\mathrm{H}_{2} \mathrm{O}\right)$ mixtures having negative values. The electrostriction volumes increase in negativity on increasing the percentages of the organic solvent, indicating the more work (energy) is done by the solvent on the solvation sheaths of the salts.

\section{Calculation of the Solvated Radii}

The solvated radii of the organic-aqueous mixtures; (EtOH- $\mathrm{H}_{2} \mathrm{O}$ ) at different temperatures (293.15, 298.15, 303.15 , and $308.15 \mathrm{~K}$ ) were calculated using Equation (11) by considering the spherical form of the solvated molecules. ${ }^{[21,22]}$

$\mathrm{V}=\frac{1}{6} \pi \mathrm{N} \sigma^{3}$

Where, $\mathrm{V}$ is the molar volume calculated from the densities as described before and $\sigma$ is the solvated diameter. The solvated radii of BDPA in mixtures were calculated by adding the crystal radius of the salt to the radii of solvent
Table 7: Molar volume (V), Van der Waals volume $\left(\mathrm{V}_{\mathrm{w}}\right)$, electrostriction volume $\left(\mathrm{V}_{\mathrm{e}}\right)$, and solvated radii $\left(r_{0}\right)$ of BDPA in different $\left(\mathrm{EtOH}-\mathrm{H}_{2} \mathrm{O}\right)$ mixed solvents at $303.15 \mathrm{~K}\left(\mathrm{~cm}^{3} \cdot \mathrm{mol}^{-1}\right)$

\begin{tabular}{lcccc}
\hline EtOH vol. $\%$ & $\mathbf{v}$ & $\mathbf{v}_{w}$ & $\mathbf{v}_{\mathrm{e}}$ & $\mathbf{r}_{\mathrm{o}}$ \\
\hline 0 & 363.97 & 240.58 & -123.4 & 4.4357 \\
20 & 518.32 & 342.61 & -175.7 & 4.9954 \\
40 & 538.98 & 356.26 & -182.7 & 5.0616 \\
60 & 563.61 & 372.54 & -191.1 & 5.1375 \\
80 & 594.71 & 393.10 & -201.6 & 5.2314 \\
100 & 612.02 & 404.54 & -207.5 & 5.2853 \\
\hline
\end{tabular}

Table 8: Molar volume (V), Van der Waals volume $\left(\mathrm{V}_{w}\right)$, electrostriction volume $\left(V_{e}\right)$, and solvated radii $\left(r_{0}\right)$ of BDPA in different $\left(\mathrm{EtOH}-\mathrm{H}_{2} \mathrm{O}\right)$ mixed solvents at $308.15 \mathrm{~K}\left(\mathrm{~cm}^{3} \cdot \mathrm{mol}^{-1}\right)$

\begin{tabular}{lcccc}
\hline EtOH vol. $\%$ & $\mathbf{v}$ & $\mathbf{v}_{w}$ & $\mathbf{v}_{\mathrm{e}}$ & $\mathbf{r}_{\mathrm{o}}$ \\
\hline 0 & 343.76 & 227.22 & -116.5 & 4.3527 \\
20 & 517.18 & 341.85 & -175.3 & 4.9913 \\
40 & 538.00 & 355.6 & -182.4 & 5.0587 \\
60 & 562.02 & 371.49 & -190.5 & 5.1329 \\
80 & 591.21 & 390.78 & -200.4 & 5.2215 \\
100 & 609.49 & 402.87 & -206.6 & 5.2784 \\
\hline
\end{tabular}

in BDPA (EtOH- $\left.\mathrm{H}_{2} \mathrm{O}\right)$ mixtures at different temperatures $(293.15,298.15,303.15$, and $308.15 \mathrm{~K})$.

The calculated values of the solvated radii of BDPA (EtOH- $\left.\mathrm{H}_{2} \mathrm{O}\right)$ mixtures at different temperatures (293.15, $298.15,303.15$, and $308.15 \mathrm{~K}$ ) as well as the solutions of BDPA in $\left(\mathrm{EtOH}-\mathrm{H}_{2} \mathrm{O}\right)$ mixtures are listed in Tables 5-8.

It is obvious that the solvated radii of BDPA in (EtOH- $\left.\mathrm{H}_{2} \mathrm{O}\right)$ mixtures are increased as the organic solvent content increase and as the temperature increase. This may be due to the excess solvation processes, and the higher solvated radii of the organic solvent used than those of water and also to increasing in the electronic clouds around the solvated molecules as a result of the increase in their vibration and rotation motions with increasing the temperature.

\section{CONCLUSION}

In this work, we calculate ion-ion interaction, dielectric constant, density of organic-aqueous mixtures of ethanolwater solvents, density of saturated solutions of BDPA, salvation volumes (Van der Waals volume $\mathrm{V}_{\mathrm{W}}$, molar volume $\mathrm{V}_{\mathrm{M}}$, and electrostriction volume $\mathrm{V}_{\mathrm{e}}$ ), and solvated radii from solubility experiments. It was found that values of the $\log \gamma_{ \pm}$of BDPA in $\left(\mathrm{EtOH}-\mathrm{H}_{2} \mathrm{O}\right)$ mixture were decreases by increasing in the content of the organic solvent used $(\mathrm{EtOH})$. The values of the $\log \gamma_{ \pm}$found to decrease with the increase in temperature. The densities of the saturated solutions of BDPA decrease by increasing ratio of EtOH and also increase by increasing in temperature. The values of the molar volume of ethanol mixtures with 
water are increased by increasing the organic solvents content in the mixtures due to the increase in the volume of organic solvent compared to water. All the electrostriction volumes calculated for BDPA having negative values. The electrostriction volumes increase in negativity on increasing the percentages of the organic solvent. The solvated radii of BDPA are increased as the organic solvent content increase and as the temperature increase.

\section{REFERENCES}

1. Yalkowsky SH, Roseman TJ. In: Techniques of Solubilization of Drugs. Ch. 3. New York: Dekker; 1981.

2. Paruta AN, Sciarrone BJ, Lordi NG. Solubility of salicylic acid as a function of dielectric constant. J Pharm Sci 1964;53:1349-53.

3. Martin A, Newburger J, Adjei A. New solubility equation. J Pharm Sci 1979;68:4-5.

4. Martin A, Paruta AN, Adjei A. Extended Hildebrand solubility approach: Methylxanthines in mixed solvents. J Pharm Sci 1981;70:1115-9.

5. Martin E, Yalkowsky SH, Wells JE. Fusion of disubstituted benzenes. J Pharm Sci 1979;68:565-8.

6. Ruckenstein E, Shulgin I. Solubility of drugs in aqueous solutions Part 1. Ideal mixed solvent approximation. Int J Pharm 2003;258:193-201

7. Scatchard G. Equilibria in nonelectrolyte solutions in relation to vapor pressures and densities of the components. J Pharm Sci 1933;61:983-4.

8. Yalkowsky SH. Solubility and Solubilization in Aqeuous Media. New York: Oxford University Press; 1999.

9. Gomaa EA, Elleef EM, Helmy ET. Conductance studies on complex formation between $\mathrm{CaCl}_{2}$ and ampicillin as ligand in water and in methanol solvent at different temperatures. Res Rev Pharm Pharm Sci 2014;3:55-64.

10. Gomaa EA, Abouelleef EM, Helmy ET. Complexation of 2-mercaptoimidazol with some barium salts conductometrically in various solvent at different temperatures. Int J Mod Chem 2015;7:141-55.
11. Gomaa EA, Abouelleef EM, Helmy ET. Solvent effects on the thermodynamics of solvation of barium diphenylamine sulfonate in ethanol-water mixed solvents. South Braz J Chem 2013;21:31-40.

12. Helmy ET, Gomaa EA, Elleef EM, Negm A. Conductometric spectrophotometric and in-vivo investigation of the interaction of $\mathrm{Ca}$ (II) Ion with oxytetracycline hydrochloride. Int J Pharm Med Biol Sci 2015;4:197-203.

13. Helmy ET, Gomaa EA, Eleef EM. Gibbs free energy and activation free energy of complexation of some divalent cations with ampicillin in methanol at different temperatures. Am J Appl Ind Chem 2016;2:29-32.

14. Aghaie M, Samaie E. Molecular dynamics study of $\mathrm{CaCl}_{2}$ in liquid methanol. J Mol Liq 2006;126:72.

15. Aghaie M, Ghaemi AF, Giahi M. Thermodynamic study of ion-association in $\mathrm{KNO}_{3}$ solution in the mixed solvent(water+methanol). J Phys Theor Chem 2005;2:33.

16. Aghaie H, AliABA2di A, Sohrabi B, Aghaie M, Sohrabi MR. Binding data analysis for interaction of $\mathrm{n}$-alkyl sulfates with insulin. J Phys Theor Chem 2004;1:143.

17. Aghaie M, Gafoorian S, Broojeni BS, Aghaie H. The effect of dielectric constant and ionic strength on the solubility of lithium carbonate at $25.0^{\circ} \mathrm{C}$ in thermodynamic view. J Phys Theor Chem 2009;5:223.

18. Aghaie $M$, Aghaie $H$, Ebrahimi A. Thermodynamics of the solubility of barium nitrate in the mixed solvent, ethanol + water, and the related ion-association. J Mol Liq 2007;135:72.

19. Gomaa EA. Solvation parameters for sodium oxalate in mixed ethanol-water solvents at $301.15 \mathrm{k}$. Eur Chem Bull 2013;1:254-61.

20. El-khouly AA, Gomaa EA, El-leef SA. Apparent association constants of $\mathrm{HgCl}_{2}$ association constants from conductivity. Bull Electrochem 2003;19:193-202.

21. Acree WE Jr. Thermodynamic Properties of Nonelectrolyte Solutions. Orlando: Harcourt Brace Javanovich, Publishers; 1984.

22. Padova J, Abrahamer I. Ion-solvent interactions. VII. Apparent and partial molal volumes of some symmetrical tetraalkylammonium halides in anhydrous methanol solutions. J Phys Chem 1967;71:2112. 